\title{
Utilizing Recycled Polypropylene Fibers as Reinforcement for Concrete Beams
}

\author{
Khadra Bendjillali \\ bendjilalik@yahoo.fr \\ Laboratory of Structures Rehabilitation and Materials, University Amar Telidji, Laghouat, Algeria
}

\author{
Mourad Hadjoudja \\ hadjoudja m@yahoo.fr \\ Laboratory of Civil Engineering Research, University Amar Telidji, Laghouat, Algeria
}

\section{Mohamed Chemrouk}

mchemrouk@yahoo.fr

Faculty of Civil Engineering, University of Science and Technology Houari Boumediene, Algiers, Algeria

\begin{abstract}
Polypropylene (PP) fibers are among numerous plastic waste materials, which are generated by the different industrial and domestic activities. Due to its low biodegradability, plastic waste constitutes a real environmental problem. The valorization of recycled PP fibers in the fabrication of concrete is one of the efficient solutions to cater for the environmental problems induced by plastic waste. In this experimental work, the workability and the mechanical properties of concrete are examined with different content ratios of recycled PP fibers. The mechanical behavior and the failure mode of concrete beams reinforced with recycled PP fibers are also studied. The used PP fibers are recycled from plastic waste of PLAST BROS factory in BordjBouArreridj, in Algeria. The fiber's diameter varies between 0.7 and $0.9 \mathrm{~mm}$. The various fiber content ratios tested in this investigation are $0.25,0.5$ and $1 \%$. Based on the results of this study, the presence of recycled PP fibers in concrete decreases its workability; the addition of an adequate superplasticizer to the concrete mix becomes then necessary. Nevertheless, a positive effect is observed on its mechanical behavior. Indeed, in the presence of steel bars, reinforcing concrete beams with recycled PP fibers improves greatly their ductility and delays the appearance of cracks.
\end{abstract}

Keywords: Recycled fibers; Polypropylene fibers; Workability of fresh concrete; Mechanical strength; Ductility

\section{INTRODUCTION}

The greatest benefit obtained by utilizing fibers as reinforcement of concrete elements is the improvement of the long-term serviceability of constructions. The presence of fibers into concrete is a very effective technique to control cracking and to improve the tensile behavior, the ductility and the durability of structures. Many types of fibers such as in metals, in synthetic and in vegetables have been used in concrete. Synthetic fibers of polypropylene (PP) are the most common commercial products in fiber reinforced concrete (Yin et al., 2015). Recently, numerous reports and papers investigating the use of PP fibers in concrete were published. PP fibers which are produced from homopolymer polypropylene resin are flexible and hydrophobic materials possessing excellent chemical and wear resistances; compared to other types of fibers, they have a lower 
coast. PP fibers are very effective in controlling plastic shrinkage cracking in concrete (Banthia \& Gupta, 2006). In addition to reducing the shrinkage of concrete (Sun \& Xu, 2009) and improving its cracking resistance (Zhang \& Zhao, 2012), PP fibers reduce the permeability of concrete that can significantly affect the lifespan of structures and delay their degradation (Kakooei, 2012). Reinforcing beams by PP fibers gives them the capability to support further loads beyond the first cracking (ACI 544.1R-96, 2002). With a minimal conventional steel reinforcement, the use of $0.5 \%$ of PP fibers can offer a better mechanical behavior in shear and in flexion of concrete beams (Bendjillali \& Chemrouk, 2018). For small crack opening ranges, PP fibers exhibited a high postcracking toughness (Caggiano, 2016). In Algeria, a large quantity of plastic fibers is wasted in certain factories and can be recycled by the construction industry to improve the concrete properties. In addition, the recycling of this waste participates successfully to solve some environmental problems and then protect the nature. Several researchers have tested the use of some plastic waste fibers in concrete and the results were very encouraging.

The main objectives of this paper are first to study the influence of the addition of recycled PP fibers on the fresh as well as hardened properties of concrete. The paper looks particularly at their role in the improvement of the mechanical behavior of concrete beams having a conventional steel reinforcement.

\section{CONCRETE MIXING INGREDIENTS}

Limestone crushed aggregates coming from OUAZANE crushing station in Laghouat (Algeria) and consisted of sand $(0 / 3 \mathrm{~mm})$ and two fractions of gravel $(3 / 8$ and $8 / 16 \mathrm{~mm})$ are used for the fabrication of tested concrete specimens. Portland cement CEM II/B$42.5 \mathrm{~N}$ produced by LAFARGE of Hammam Dalaa factory in M'Sila (Algeria) is used with potable water and high-range water-reducing admixtures, type SIKAVISCORETE TEMPO 12 fabricated by SIKA EL DJAZAIR. The polypropylene fibers used as reinforcement of the tested concrete are recycled from plastic waste (Figure 1) of PLAST BROS, a factory situated in BordjBouArreridj (Algeria). Fibers have a length of $50 \mathrm{~mm}$ and diameters between 0.7 and $0.9 \mathrm{~mm}$. The sand has a fineness modulus of 2.73 and a sand equivalent of $74 \%$. The water absorption varies between $3.8,1.5$ and $1.8 \%$ for sand, gravel $3 / 8$ and gravel $8 / 16$ respectively.

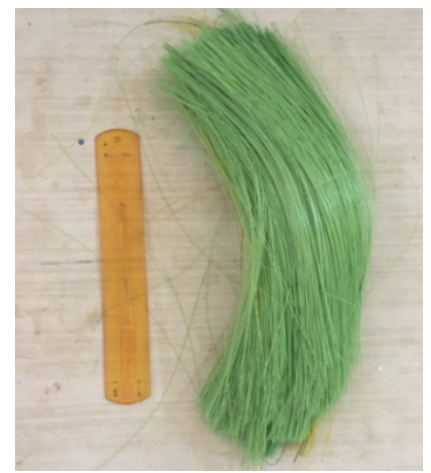

Figure 1: Polypropylene fibres used in the present tests 


\section{PREPARATION AND CURING OF THE CONCRETE SPECIMENS}

The concrete mixture is prepared using Pierre Rossi optimization based on BaronLesage method; with a water to cement $\mathrm{W} / \mathrm{C}$ ratio of 0.6 and a sand to gravel ratio $\mathrm{S} / \mathrm{G}$ of 0.65 . The superplasticizer is added for improving the concrete workability (slump $=$ $9 \mathrm{~cm})$. The composition of the control concrete is as follows:

Cement: $350 \mathrm{~kg} / \mathrm{m}^{3}$, Sand: $663 \mathrm{~kg} / \mathrm{m}^{3}$, Gravel 3/8: $105 \mathrm{~kg} / \mathrm{m}^{3}$, Gravel 8/16: $916 \mathrm{~kg} / \mathrm{m}^{3}$, Water: $210 \mathrm{~kg} / \mathrm{m}^{3}$, Superplasticizer: $2.3 \mathrm{~kg} / \mathrm{m}^{3}$.

The same composition is used for making the recycled PP fibers concrete, where three fractions of fibers (by weight) are used: $0.25,0.5$ and 1\%. Firstly, the cement and aggregates are dry mixed in a drum concrete mixer, secondly half of the water content with the admixture are added, the fibers then are introduced and dispersed manually into the mix (Figure 2) and the remaining half of the water is added gradually at last. After demolding, the concrete specimens are cured under plastic sheets until the testing day.

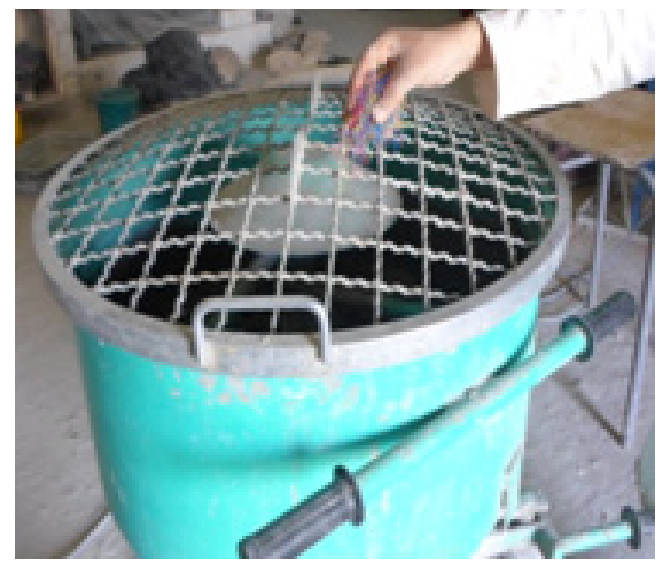

Figure 2: Adding of PP fibers

\section{FRESH CONCRETE CHARACTERISTICS}

Test results show that the concrete workability decreases as the content of recycled PP fibers is increased, especially when the fibers content is more than $0.5 \%$ (Figure 3 ).

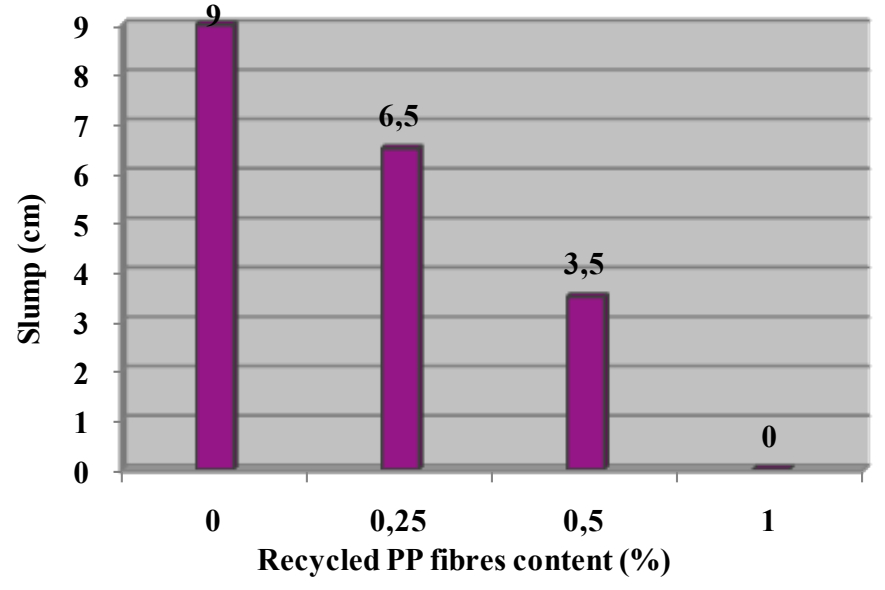

Figure 3: Variation of concrete slump 
This is due to the presence of fibers which imprison cement paste and making concrete more viscous (Figure 4) and difficult to place in the formwork. In this case, the superplasticizer amount must be increased to obtain a better workability and facilitate the concreting. Similar result was previously observed in several studies (Hsie et al., 2008; Söylev \& Özturan, 2014; Bendjillali et al., 2018). Vairagade and Kene (2013) have reported that fibers can form a network structure in concrete, which restrains mixture from segregation and flow.

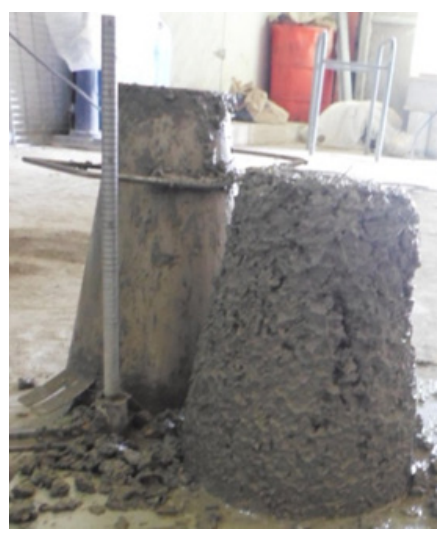

Figure 4: Slump test realized on recycled PP fibers concrete

\section{HARDENED CONCRETE CHARACTERISTICS}

The mechanical strength (flexural and compressive strength) of prismatic samples $70 \times 70 \times 280 \mathrm{~mm}$ is measured after 28 days of age, the results are presented in Figure 5.

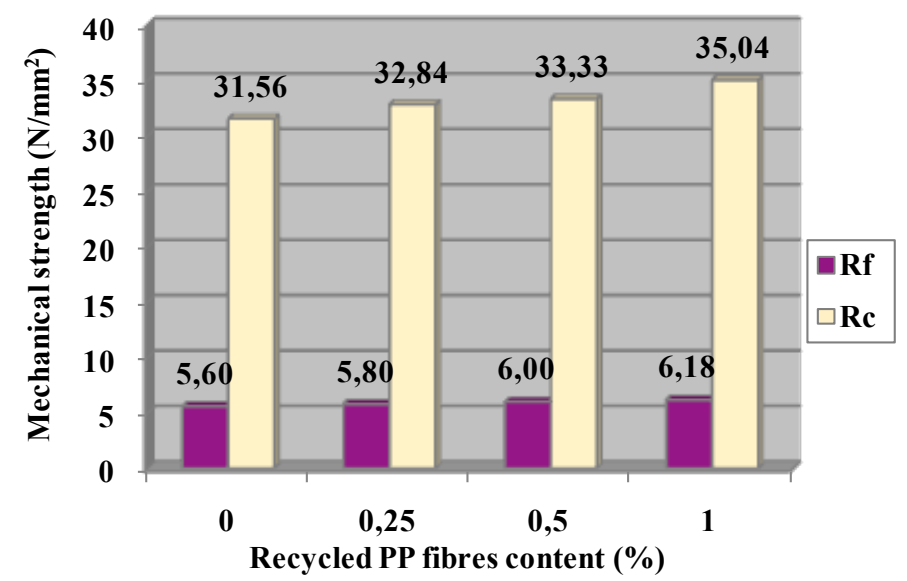

Figure 5: Mechanical strength of recycled PP fiber concrete

The improvement of the flexural strength was 3.6, 7.2 and $10.4 \%$ respectively when $0.25,0.5$ and $1 \%$ of recycled PP fibers were used as reinforcement in concrete. As shown in other works (Zhang \& Zhao, 2012; Suji et al., 2007), the increase of the flexural strength is proportional to amount of PP fibers. There is usually an optimum amount of PP fiber which results in an effective distribution of fibers in concrete and consequently 
leads to a better flexural strength (Alamshahi et al., 2012; Dharan \& Lal, 2016). For the compressive strength, the improvement ratio reaches $4.1,5.6$ and $11 \%$ in $0.25,0.5$ and $1 \%$ recycled PP fibers concrete respectively.

As reported by Naraganti et al. (2019), the compressive strength increases proportionately with the increase in the PP fibers content. This is in contradiction with some of the findings in the literature, reporting a decrease of the compressive strength with an increase in the fibers content (Meddah \& Bencheikh, 2009; Ramezanianpour et al., 2013; Sadiqul Islam \& Gupta, 2016; Das et al., 2018). However, while the effect of recycled PP fibers on the compressive strength of concrete may not seem to be considerable, nor widely accepted, their effect on the failure mode in flexure as well as in compressive, is very significant, as shown in Figure 6. Thanks to the presence of recycled PP fibers, concrete specimens failed in a noticeable ductile manner (Figure 6-b), whereas the control concrete specimens containing no fibers failed in a brittle manner (Figure 6-a). Ductility of concrete expresses the ability of the material to absorb energy in the post cracking state. Such ductile behavior exhibited by PP fibers concrete is mainly attributed to the extension of fibers and at the same time to the restraint of the crack widening by these fibers. As a result, a number of fine cracks would form at the post cracking state before failure. Such behavior was reported in several works, using numerous types of fibers (Soutsos et al., 2012; Cifuentes et al., 2013; Sahoo et al., 2015).

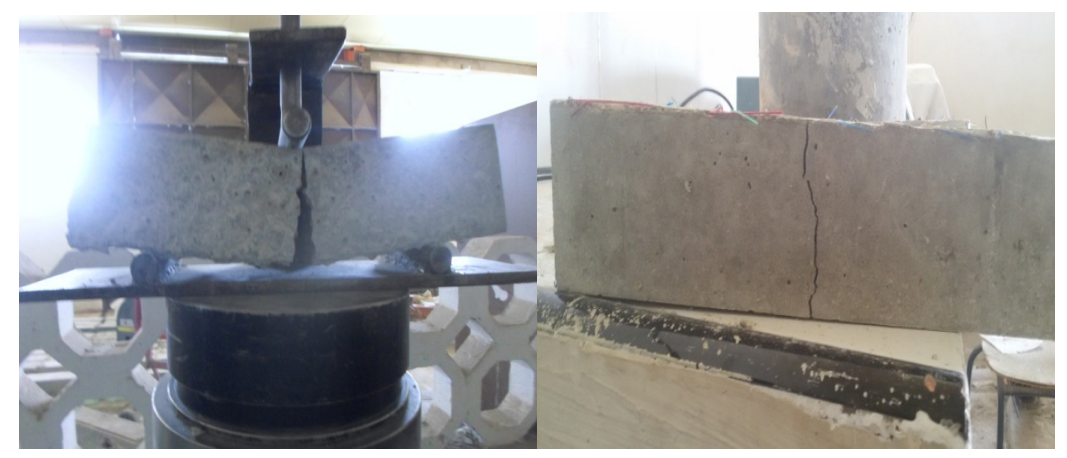

After flexural test

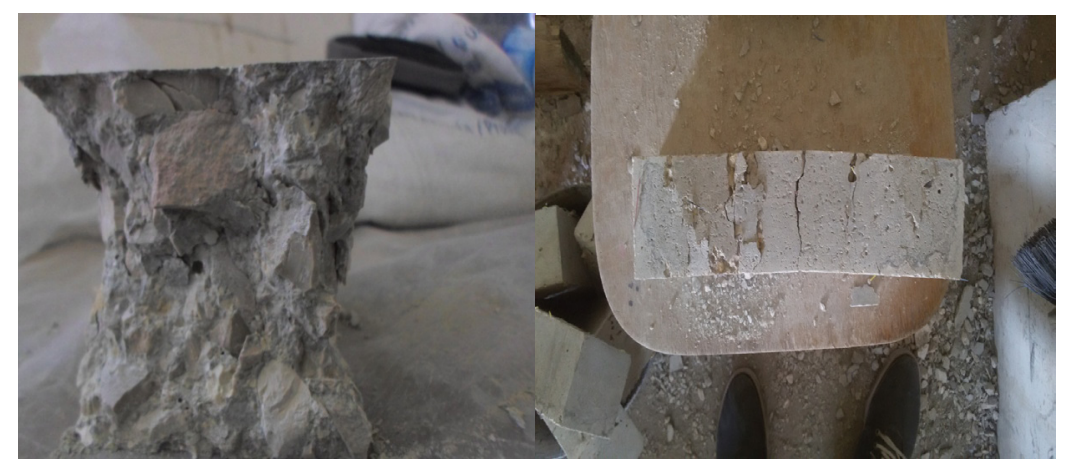

After compressive test

a: Control concrete

b: Recycled PP fibers concrete

Figure 6: Failure mode in concrete specimens 


\section{FLEXURAL BEHAVIOUR OF POLYPROPYLENE FIBERS CONCRETE BEAMS HAVING CONVENTIONAL STEEL REINFORCEMENT}

Four-point bending tests are carried out on 100x100x500mm beams having conventional reinforcement according to the schematic diagram given in Figure 7-a. The cross-section of the beam specimens is as shows in figure 7-b.

From Figure 8, the effect of recycled PP fibers is appreciated not only through the failure load of the different tested beams, but also through their first cracking load. In effect, concrete beams containing $0.25 \%$ recycled PP fibers have their first cracking load increased by $13 \%$ compared to control beam. This percentage increase reaches almost $27 \%$ for concrete beams containing $0.5 \%$ recycled PP fibers and $48 \%$ for concrete beams containing 1\% recycled PP fibers. This result is of an enormous practical importance since it reveals the high efficiency of fibers to delay the first cracking in concrete beams. Recycled PP fibers have also played an important role in increasing the failure load of concrete beam, compared to beams without fibers.

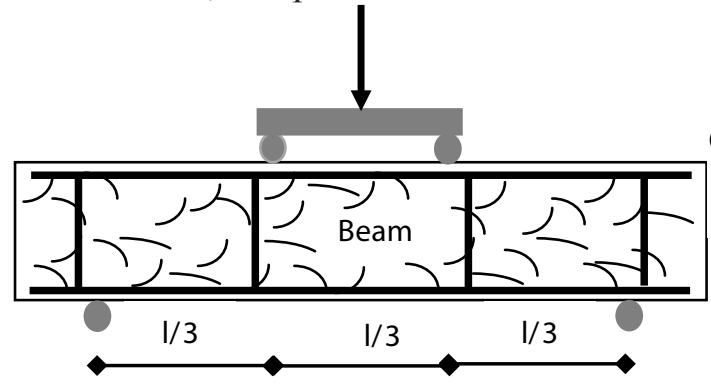

a: Schematic diagram of four point bending

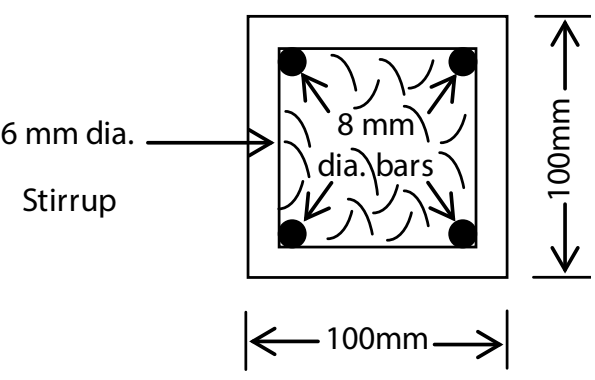

b: Cross-section of sample beam

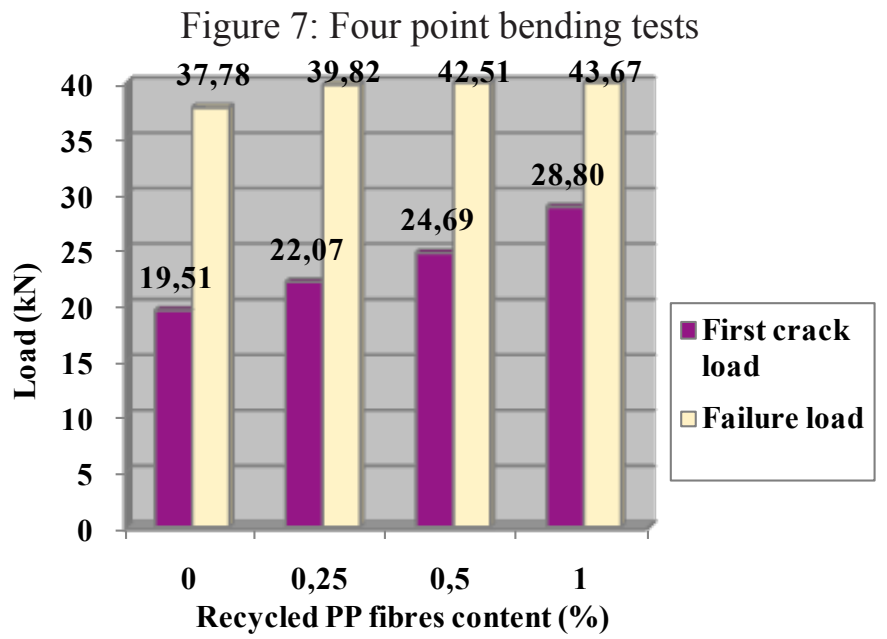

Figure 8: Variation of first cracking load and failure load of reinforced concrete beam

In effect, the failure load increased by $6 \%$ for beams containing $0.25 \%$ recycled PP fibers. For fibers contents of $0.5 \%$ and $1 \%$, the ultimate load increased by $13 \%$ and $16 \%$ respectively. Although, the reinforcement of structural elements by PP fibers improves the first cracking behavior, the efficient contribution of fibers in general appears at the 
post cracking state (Ghosni et al., 2013). When recycled PP fibers are added to concrete, the shear capacity of beams is increased (Figure 9). The recycled PP fibers concrete beams show more ductile behavior with relatively more restrained diagonal cracks (figure 9-b) compared to the control beam (figure 9-a). The used fibers have significantly reduced the width and number of shear cracks, which improves the mechanical performance of reinforced concrete beams. Some researchers (Baskar et al., 2018; Tahenni et al., 2015) have reported that with the addition of fibers, the strength and stiffness of concrete beams increase, while the cracks decrease in width and in length. The incorporation of fibers in concrete increases the cohesion of the matrix and hence the failure becomes more ductile and gradual in fiber reinforced beams (Madhavi et al., 2014). Combining PP fibers and stirrups improves the behavior of reinforced concrete beams and changes its failure mode (Ghallab \& Badr, 2006).

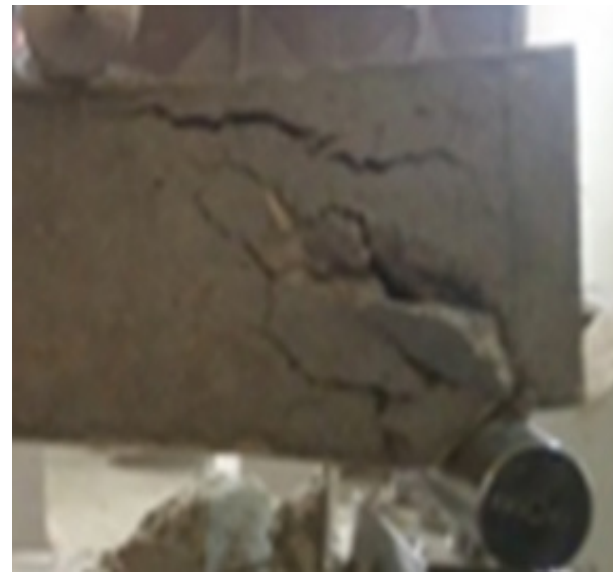

a: Control beam.

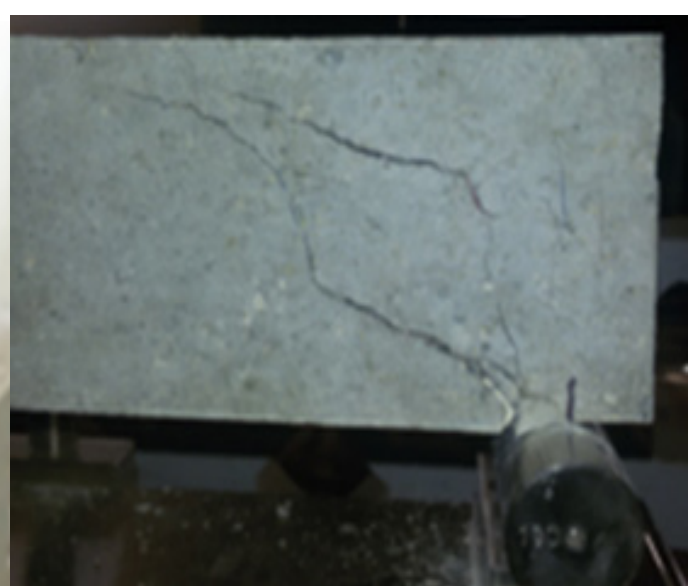

b: Recycled PP fibers concrete beam

Figure 9: Typical shear failure of the beams tested

\section{CONCLUSION}

Based on the results obtained in this investigation, the following conclusions can be made:

- The workability of concrete is negatively affected by the addition of recycled PP fibers.

- For compressive as well as flexural strength, the strength's optimum is reached at $1 \%$ of recycled PP fibers content.

- Both, the first cracking load and the failure load are significantly increased by the presence of recycled PP fibers in concrete beams.

- Beams reinforced with recycled PP fibers have exhibited higher shear strengths and showed more ductility before failure than the control beams.

\section{REFERENCES}

ACI 544.1R-96 (2002). State of the art report on fiber reinforced concrete.

Alamshahi, V., Taeb, A., Ghaffarzadeh, R. \& Rezaee, M. A. (2012). Effect of composition and 
length of PP and polyester fibres on mechanical properties of cement based composites. Construction and Building Materials, 36, 534-537.

Banthia, N. \& Gupta, R. (2006). Influence of polypropylene fiber geometry on plastic shrinkage cracking in concrete. Cement and Concrete Research, 36, 1263-1267.

Baskar, K., Elangovan, G. \& Mohan Das, K. (2018). Flexural behaviour of fibre reinforced concrete beams with different aspect ratios. FIBRES \& TEXTILES in Eastern Europe, 26, $1(127), 59-66$.

Bendjillali, K. \& Chemrouk, M. (2018). Study of the reinforcement of structure members by polypropylene fibres waste. MATEC Web of Conferences, 149, 01022.

Bendjillali, K., Chemrouk, M. \& Boulekbache, B. (2017). Recycled synthetic waste fibres for the reinforcement of concrete. WASTES-Solutions, Treatments and Opportunities II, $1^{\text {st }}$ Edition, CRC Press, 9-15.

Caggiano, A., Gambarelli, S., Martinelli, E., Nisticò, Ni. \& Pepe, M. (2016). Experimental characterization of the post-cracking response in hybrid steel/polypropylene fiber-reinforced concrete. Construction and Building Materials, 125, 1035-1043.

Cifuentes, H., García, F., Maeso, O. \& Medina, F. (2013). Influence of the properties of polypropylene fibres on the fracture behaviour of low-, normal- and high-strength FRC. Construction and Building Materials, 45, 130-137.

Das, C. S., Dey, T., Dandapat, R., Mukharjee, B. B. \& Kumar, J. (2018). Performance evaluation of polypropylene fibre reinforced recycled aggregate concrete. Construction and Building Materials, 189, 649-659.

Dharan, D. S. \& Lal, A. (2016). Study the effect of polypropylene fiber in concrete. International Research Journal of Engineering and Technology, 3(6), 616-619.

Ghallab, A. \& Badr, A. (2006). Flexural behaviour of polypropylene fibers reinforced concrete beams. Housing and Building National Research Centre Journal, 2 (3), 50-63.

Ghosni, N., Samali, B. \& Vessalas, K. (2013). Ductility and strength of reinforced concrete beams intrinsically reinforced with polypropylene fibers. The Thirteenth East Asia-Pacific Conference on Structural Engineering and Construction (EASEC-13), Sapporo, Japan.

Hsie, M., Tu, C. \& Song, P. (2008). Mechanical properties of polypropylene hybrid fiberreinforced concrete. Materials Science and Engineering A, 494, 153-157.

Kakooei, S., Akil, H. M., Jamshidi, M. \& Rouhi, J. (2012). The effects of polypropylene fibers on the properties of reinforced concrete structures. Construction and Building Materials, 27, 73-77.

Madhavi, T. Ch., Raju, L. S. \& Mathur, D. (2014). Polypropylene fiber reinforced concrete- A Review. International Journal of Emerging Technology and Advanced Engineering, 4(4), 114-119.

Meddah, M. S. \& Bencheikh, M. (2009). Properties of concrete reinforced with different kinds of industrial waste fiber materials. Construction and Building Materials, 23, 3196-3205.

Naraganti, S. R., Pannem, R. M. R. \& Putta, J. (2019). Impact resistance of hybrid fibre reinforced concrete containing sisal fibres. Ain Shams Engineering Journal, 10(2), 297-305.

Ramezanianpour, A. A., Esmaeili, M., Ghahari, Seyed-Ali \& Najafi, M. (2013). Laboratory study on the effect of polypropylene fiber on durability, and physical and mechanical characteristic of concrete for application in sleepers. Construction and Building Materials, 44, 411-418.

Sadiqul Islam, G. M. \& Gupta, S. D. (2016). Evaluating plastic shrinkage and permeability 
of polypropylene fiber reinforced concrete. International Journal of Sustainable Built Environment, 5, 345-354.

Sahoo, D. R., Maran, K. \& Kumar, A. (2015). Effect of steel and synthetic fibers on shear strength of RC beams without shear stirrups. Construction and Building Materials, 83, 150-158.

Soutsos, M. N., Le, T. T. \& Lampropoulos, A. P. (2012). Flexural performance of fibre reinforced concrete made with steel and synthetic fibres. Construction and Building Materials, 36, 704710 .

Söylev, T. A. \& Özturan, T. (2014). Durability, physical and mechanical properties of fiberreinforced concretes at low-volume fraction. Construction and Building Materials, 73, 67-75.

Suji, D., Natesan, S. C. \& Murugesan, R. (2007). Experimental study on behaviors of polypropylene fibrous concrete beams. J Zhejiang Univ Sci A, 8(7), 1101-1109.

Sun, Z. \& Xu, Q. (2009). Microscopic, physical and mechanical analysis of polypropylene fiber reinforced concrete. Materials Science and Engineering A, 527, 198-204.

Tahenni, T., Chemrouk, M. \& Lecompte, T. (2016). Effect of steel fibers on the shear behavior of high strength concrete beams. Constructions and Building Materials, 105, 14-28.

Vairagade, V. \& Kene, K. (2013). Strength of normal concrete using metallic and synthetic fibers. Procedia Engineering, 51, 132-140.

Yin, S., Tuladhar, R., Shi, F., Combe, M., Collister, T. \& Sivakugan, N. (2015). Use of macro plastic fibres in concrete: A review. Construction and Building Materials, 93, 180-188.

Zhang, S. \& Zhao, B. (2012). Influence of polypropylene fibre on the mechanical performance and durability of concrete materials. European Journal of Environmental and Civil Engineering, 16(10), 1269-1277. 